\title{
Effects of Indomethacin on Fetal Rat Lungs: A Possible Cause of Persistent Fetal Circulation (PFC)
}

\author{
LEE C. HARKER, STANLEY E. KIRKPATRICK, ${ }^{(48)}$ WILLIAM F. FRIEDMAN, ${ }^{(49)}$ AND \\ COLIN M. BLOOR ${ }^{(50)}$ \\ Departments of Pathology and Pediatrics, University of California, San Diego, School of Medicine, \\ La Jolla, California, USA
}

\begin{abstract}
Summary
Indomethacin, because of its prostaglandin inhibition, may cause constriction of the ductus arteriosus and affect the pulmonary circulation. To study this possibility, we gave indomethacin daily by gavage to two groups of pregnant rats from the 17 th day of pregnancy through delivery (group 1,2 mg/kg/day; group $2,4 \mathrm{mg} /$ $\mathrm{kg}$ /day). Group 3 , untreated control pregnant rats, received saline. The pups were killed 30 min after birth and heart-lung preparations were perfused with glutaraldehyde. Appropriate blocks were processed for quantitative morphometry of the pulmonary arteries and arterioles. For analysis, the vessels were grouped by external diameter, i.e., $<30,30$ to 50 , and 50 to $100 \mu \mathrm{m}$. Groups 1 and 2 showed an increased medial smooth muscle mass in both 30 to $\mathbf{5 0}$ and 50 to $100-\mu \mathrm{m}$ vessels as indicated by medial thickness and medial areas $(P<0.05)$. Muscularized arterioles, $<30 \mu \mathrm{m}$, were present in groups 1 and 2 , but not in controls. The relative mass of lung parenchymal components were determined by point counting. Indomethacin-treated animals had an increased saccular wall mass, decreased airspace mass, and a decreased capillary to saccular wall ratio $(P<0.05)$. These results show that the fetal pulmonary circulation's response to indomethacin comprises the appearance of medial hypertrophy and newly muscularized arterioles. When these changes occur in lungs with immature, thick saccular walls, there is a decreased surface for oxygen exchange and an increased pulmonary vascular resistance resulting in a persistent fetal circulation.
\end{abstract}

\section{Speculation}

Indomethacin, during pregnancy, may cause constriction of the ductus arteriosus and induce a persistent fetal circulation in the newborn. Inasmuch as salicylates also may be causative agents of persistent fetal circulation, their use by pregnant women should be carefully examined.

Indomethacin, a potent prostaglandin synthetase inhibitor used to prevent premature labor, has been shown in studies from our laboratory and others $(10-12,18,24,36,42)$ to constrict the patent ductus arteriosus of the fetus when administered to the mother. Such partial constriction of the patent ductus arteriosus in utero would divert blood into the lungs and away from the descending aorta which would be disadvantageous for fetal oxygenation. To maintain fetal oxygenation, a compensatory increase in pulmonary vascular resistance may occur which would keep pulmonary blood flow low and increase blood flow through the ductus arteriosus into the descending aorta to maintain adequate levels of placental blood flow. Such changes could induce morphologic changes in the vessel walls of the pulmonary circulation resembling those observed in persistent fetal circulation (PFC). Thus, to evaluate the possible role of indomethacin in inducing the PFC syndrome, we conducted quantitative morphometric measurements on pulmonary vessels obtained from newborn animals whose mothers received indomethacin during pregnancy and compared these measurements to control newborn animals whose mothers received a placebo.

\section{MATERIALS AND METHODS}

Eight Sprague-Dawley female rats who were littermates (Hill Top Lab Animals) were impregnated on the same day. These animals were randomly assigned to one of three groups. Group 1 $(N=3)$ received indomethacin at a dose of $2 \mathrm{mg} / \mathrm{kg} /$ day. Group $2(N=3)$ received indomethacin at a dose of $4 \mathrm{mg} / \mathrm{kg} /$ day. Group $3(N=2)$ received equivalent volumes of sterile water and served as controls. The indomethacin solution was mixed fresh daily, and the various solutions given by ball-tipped gavage needle. The dams were dosed from day 17 of pregnancy until delivery, a period selected to correspond to the last 2 to 3 months of a human pregnancy.

\section{AUTOPSY STUDIES}

Newborn rats were killed within $30 \mathrm{~min}$ of birth by intraperitoneal injection of phenobarbital. The chest was opened, and the rib cage was removed. The ductus arteriosus was examined for patency using a dissecting microscope. In all animals, it appeared closed. In the indomethacin-treated animals, the ductus arteriosus was smaller than in control animals. A needle was tied in the trachea, and a needle was inserted into the right ventricle. Both were simultaneously given injections of $3 \%$ glutaraldehyde in cacodylate buffer until the lungs were fully distended, and there was blanching of the pulmonary vascular bed. The removed heartlung preparation was then fixed in the glutaraldehyde for $2 \mathrm{hr}$ and then put into the cacodylate buffer, $\mathrm{pH} 7.2$ (27). One $\mu \mathrm{m}$-thick slices were prepared from appropriate blocks and stained with toluidine blue for microscopic examination. At least 10 sections per animal were prepared for quantitative morphometric measurements. The histologic slides were coded so that their origins were unknown to the grading observer.

\section{MORPHOMETRIC MEASUREMENTS AND ANALYSIS}

Pulmonary arteries were distinguished from veins as follows: (1) for a given diameter, veins have less muscle and more connective tissue than arteries; (2) in a muscular vein, there is no internal elastic lamina; (3) the larger veins run at the edge of an acinus; (4) in a given length, small veins will have more tributaries than the arteries; and (5) after the simultaneous injection technique, only the veins should still contain red blood cells (27).

Using a camera lucida, the slides were projected at $\times 100$ magnification, and the pulmonary arteries were traced. Tracings were made from at least 10 sections from each rat pup. Quantita- 
tive morphometric measurements were made using an electronic pen (Graf Pen-3) connected to a HP 9825 programmable calculator. The measurements obtained were: external diameter, medial thickness, intimal area, and the number of intimal cell nuclei. The

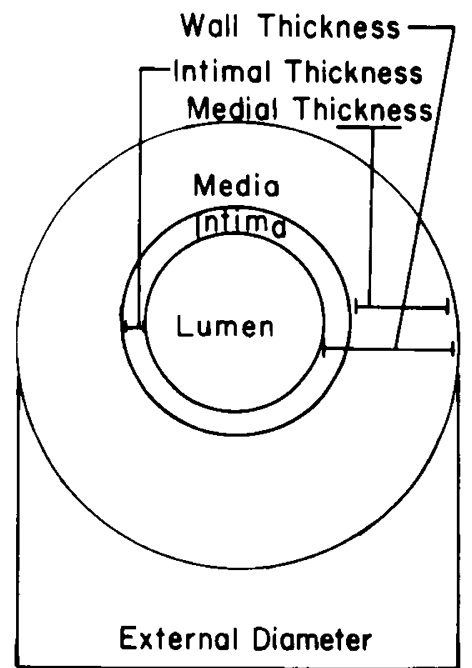

Fig. 1. Schematic diagram showing the measurements made on muscular pulmonary arteries and arterioles.

Table 1. Incidence of stillborns

\begin{tabular}{llccc}
\hline & & \multicolumn{3}{c}{ No. of pups } \\
\cline { 3 - 5 } & Group & Total & Live & Stillborn \\
\hline 1 & (Indomethacin) & 30 & 16 & $14(47)^{\prime}$ \\
2 & (Indomethacin) & 9 & 6 & $3(33)$ \\
3 & (Control) & 13 & 13 & $0(0)$ \\
\hline
\end{tabular}

' Numbers in parentheses, percent. external diameter, taken to the shortest diameter, and the other measurements $(27,29-31)$ are shown in Figure 1. Only vessels which could be clearly distinguished as arteries or arterioles with an internal elastic lamina were analyzed. Vessels were grouped for analysis by external diameter into three groups: $<30 \mu \mathrm{m}, 30$ to $50 \mu \mathrm{m}$, and 50 to $100 \mu \mathrm{m}$. From 2 to 5 vessels were analyzed in each size group from each section. At least 30 vessels in each size group were analyzed from each rat pup. The relative masses of lung parenchymal components were determined by point counting of sections of peripheral lung tissue $(28,29-31,34,35)$. An eyepiece containing a metric grid was used to examine each histologic slide. A Hewlett-Packard 9825A desk top calculator was programmed to accumulate the counted points and calculate the percentage of area of each parenchymal component. We used the formula presented by Elias et al. (7) for volume ratios using the point-counting method. This formula, modified by Page and McCallister (34) and Mobley and Page (28) is:

$$
\mathrm{V}_{\mathrm{i}} / \mathrm{V}_{\text {tisaue }}=\mathrm{P}_{\mathrm{i}} / \mathrm{P} \text { tissue }
$$

where $V_{1}=$ the volume of the component, $V_{\text {tissue }}=$ the volume of the total tissue sample, $P_{i}=$ the number of points lying on the component, and $P_{\text {tissue }}=$ the number of points lying on the total tissue sample. At least five fields were counted from each histologic slide and about 50 fields were measured from each rat pup. All results were compared to control values using Student's unpaired $t$ test (44).

\section{RESULTS}

The number of live births and stillborns occurring in the three groups are presented in Table 1 . The indomethacin-treated groups had an increased incidence of stillborns. Maternal mortality was also increased in group 2 which received the higher dose. One of the three treated dams died before delivery whereas another died within $24 \mathrm{hr}$ of delivery. No group 1 or 3 (control) animals died.

The live newborns in both indomethacin-treated groups were noticeably smaller and less mature in appearance compared to

MEDIAL THICKNESS ( $\boldsymbol{X}$ WALLL THICKNESS)

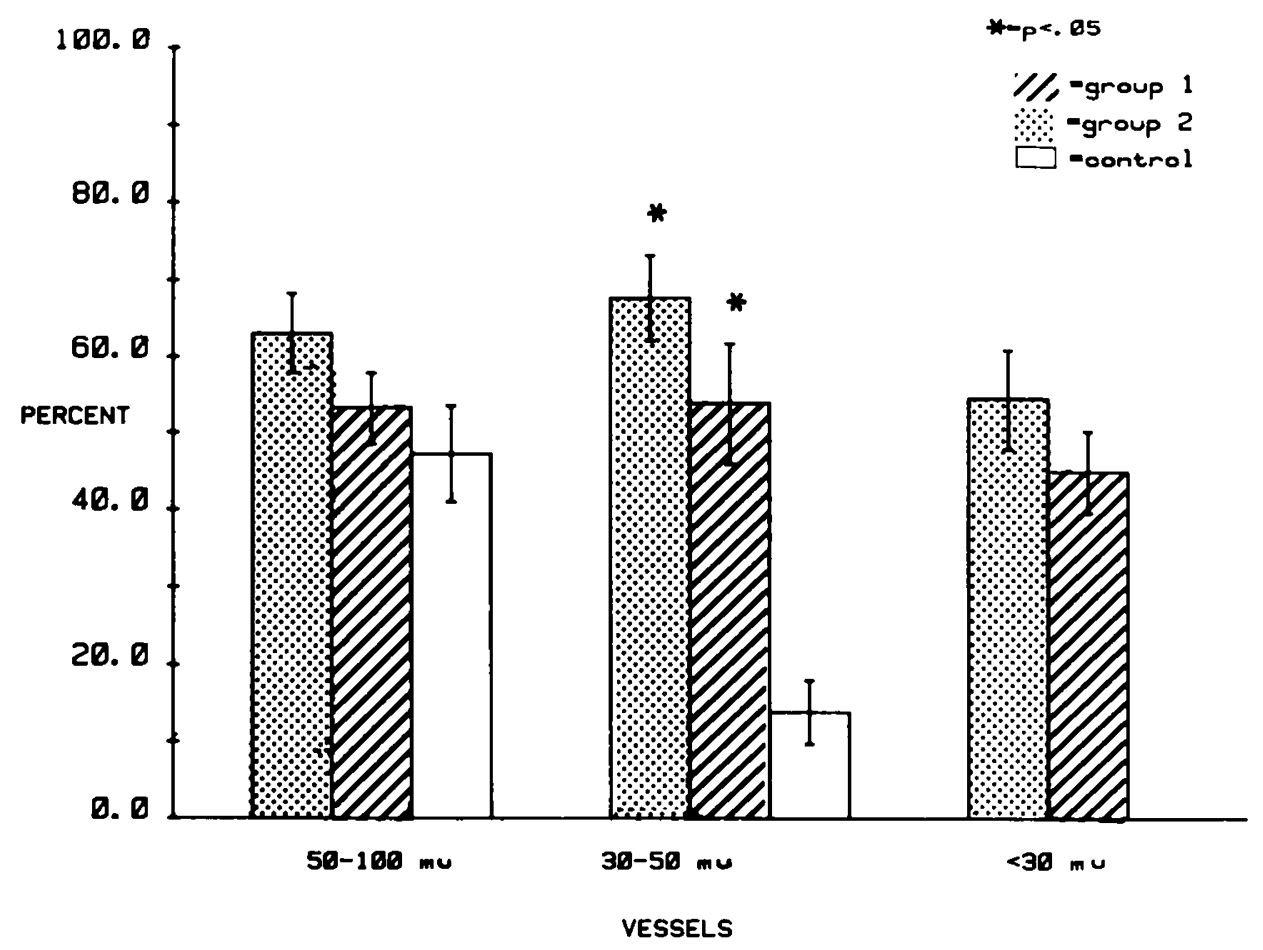

Fig. 2. Medial thickness of muscular pulmonary arteries and arterioles. Values are expressed as percentage of wall thickness. Vessels are grouped by external diameter. Groups 1 (diagonal stripes) and 2 (stippled) are indomethacin-treated groups. Bar heights indicate mean values. Vertical lines, S.E. *, significant differences from control groups. No muscularized arterioles $<30 \mu \mathrm{m}$ were seen in the control animals. 


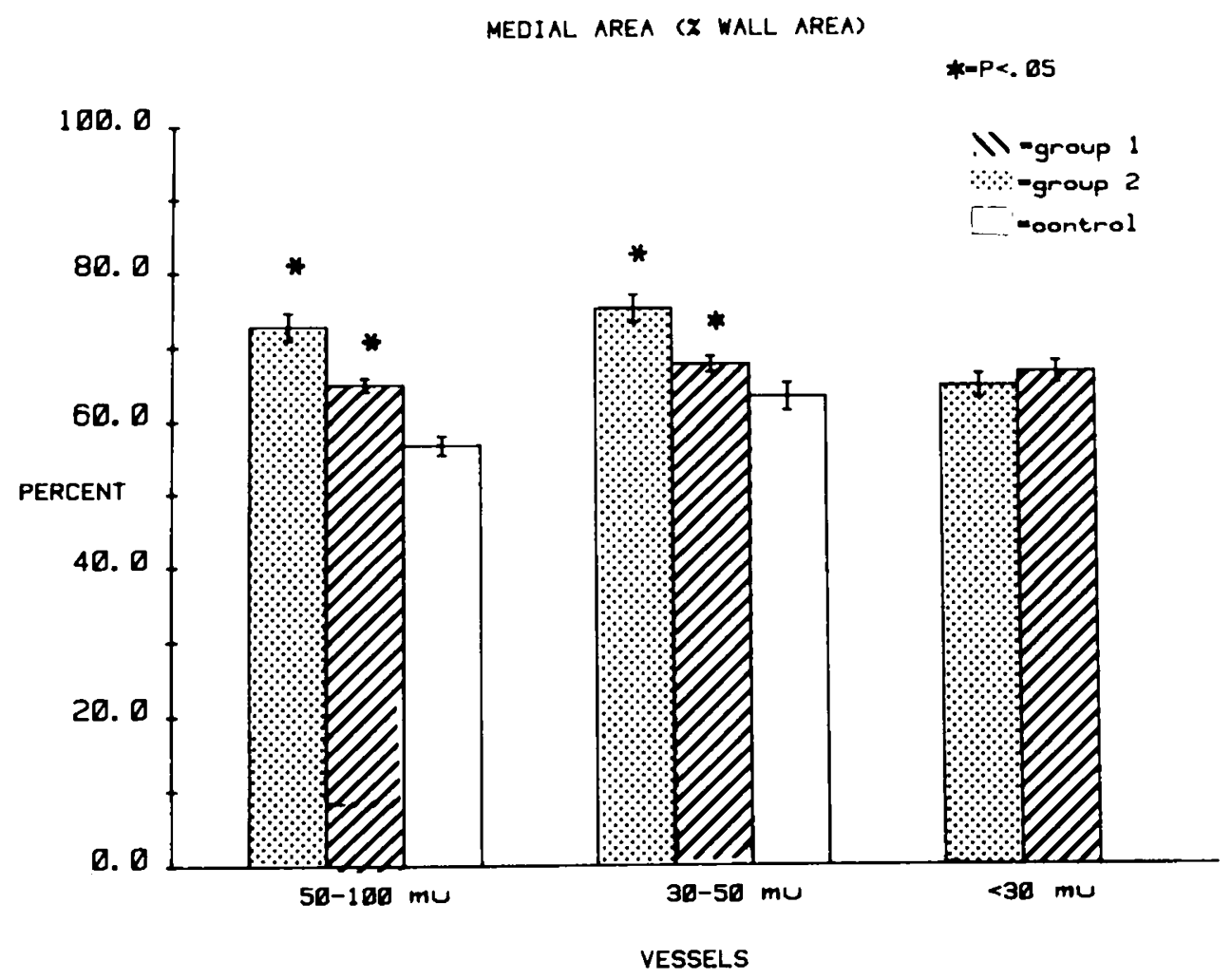

Fig. 3. Medial area of muscular pulmonary arteries and arterioles. Values are expressed as percentage of wall area. Legend same as Figure 2.

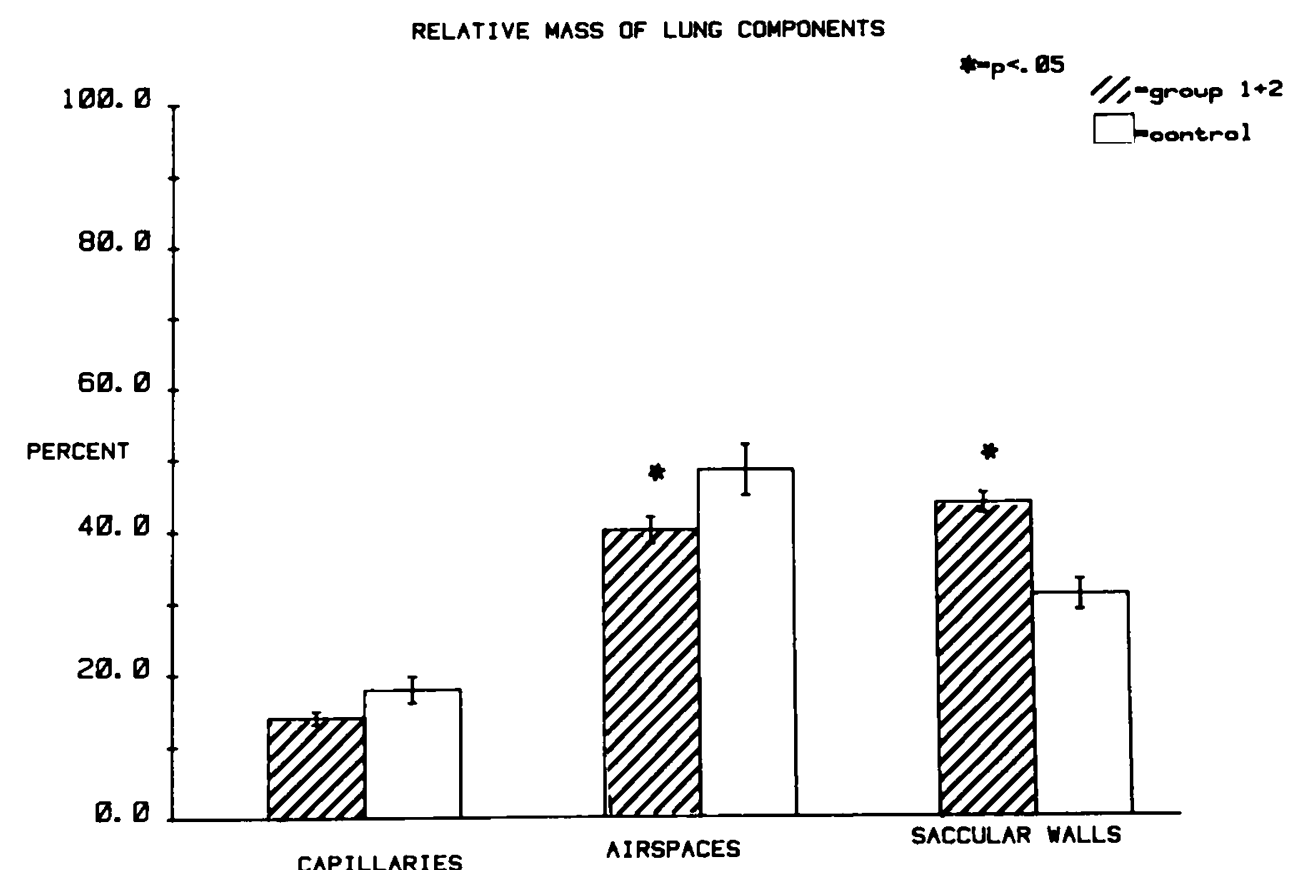

Fig. 4. Relative mass of lung components in indomethacin-treated (diagonal stripes) and control (open bar) animals. Values are expressed as percentage of total lung mass. Bar heights indicate mean values. Vertical lines, S.E. *, significant differences from control group.

controls. The stillborn animals did not appear macerated or less mature than their littermates, nor did they give any indication that they had died long before birth.

\section{PULMONARY VASCULAR CHANGES}

The quantitative morphometric measurements of pulmonary arteries and arterioles of the newborn animals are presented in Figures 2 and 3 . Arteries from groups 1 and 2 showed an increased medial smooth muscle mass in 30 to 50 and 50 to $100 \mu \mathrm{m}$ vessels.
The 30 to $50 \mu \mathrm{m}$ vessels had increased medial thickness and medial area whereas the 50 to $100 \mu \mathrm{m}$ vessels showed an increased medial area. Muscularized arterioles, $<30 \mu \mathrm{m}$ in diameter, were present in both groups 1 and 2, but were not found in group 3 control.

\section{PULMONARY PARENCHYMAL CHANGES}

The relative mass of lung parenchymal components, i.e., capillaries, air spaces, and saccular walls, are shown in Figure 4. There 


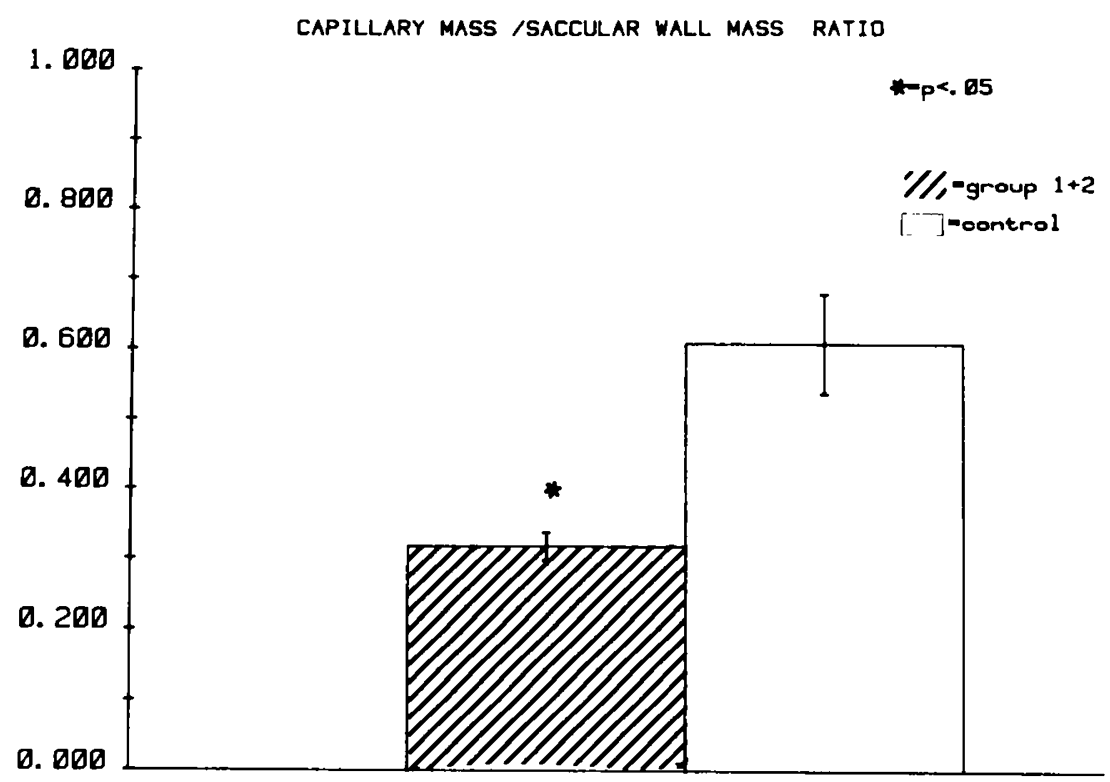

Fig. 5. Capillary mass/saccular wall mass ratio. Legend same as in Figure 4.

was no difference $(P<0.5)$ between groups 1 and 2 , so the indomethacin-treated animals were grouped together and compared to the controls. The relative mass of capillaries was similar in treated and control animals, but the indomethacin-treated animals showed an increased saccular wall mass $(P<0.001)$ and a decreased air space mass $(P<0.05)$. There was also a significant $(P<0.001)$ decrease of the capillary mass/saccular wall mass ratio in the treated animals (Fig. 5). These findings are similar to those observed in immature lungs and result in decreased surface for oxygen exchange.

\section{DISCUSSION}

Prostaglandin synthetase inhibitors given directly to the mammalian fetus $(10-12,18)$ or indirectly via maternal dosage $(24,36$, 41,42 ) are known to cause constriction or closure of the fetal ductus arteriosus. An increasing sensitivity to these agents has been shown as the fetus nears term (42). Constriction of the ductus arteriosus causes fetal pulmonary hypertension $(11,18)$ which leads to the development of increased amounts of pulmonary vascular smooth muscle (22).

Premature closure of the ductus arteriosus as a cause of neonatal cardiopulmonary distress was first noted in 1969 (1) and over the next decade has become recognized more and more. Estimates of frequency indicate it may be as high as $1 / 1454$ births (37) and a cause of neonatal death in 1/8666 births (19).

In the early 1970's, a syndrome called PFC was recognized and defined as the clinical presentation of cyanosis and other signs of respiratory distress secondary to cardiovascular problems but without organic heart disease, and the presence of right to left shunting across the ductus arteriosus and/or foramen ovale secondary to a persistent increased pulmonary vascular resistance (13). The PFC syndrome was first reported by Arcilla et al. (1) in the infant of a mother treated for 2 wk with salicylates. Four main etiologies, i.e., hyperviscosity, hypoglycemia, a typical respiratory distress syndrome, and idiopathic were proposed. During 19761977, multiple articles about PFC were published, in which infants with recognized and treatable causes such as hyperviscosity or hypoglycemia were excluded, and effort was focused on the idiopathic category (21). A clearer picture emerged of PFC in these infants; some thought it to be a complication of transient tachypnea of the newborn (2), and initially, it seemed to be relatively nonserious and transient syndrome. More experience showed however that some of these infants presented with evidence of myocardial dysfunction as well as congestive heart failure $(33,39)$, transient tricuspid insufficiency $(3,41)$, and/or echocardiographic changes indicative of biventricular dysfunction or right ventricular dysfunction alone (38). In these groups, mortality ranged from 20 to $36 \%(33,37,45)$. Although transient tricuspid insufficiency may be directly related to birth or prenatal asphyxia and consequent papillary muscle ischemia or infarction, Levin et al. (21) have angiographically demonstrated its occurrence in patients with PFC. The phenomena of increased arterial muscle mass was noted by Haworth and Reid (16) and the idea of premature ductal closure as a cause was first raised. The changes in arterial muscle mass was pursued, primarily by Levin et al. $(20,23)$, in PFC associated with aortic coarctation or diaphragmatic hernia (32). Reports of PFC in newborns of mothers receiving indomethacin prompted further investigation with the resulting recent paper by Levin et al. on the pulmonary, hemodynamic, and myocardial changes in fetal lambs whose ductus was constricted by maternal dosage with indomethacin (25). Our results in this paper show that both medial hypertrophy and newly muscularized arterioles appear. When these changes occur in lungs with immature, thick saccular walls (4) as were seen in the indomethacin-treated animals, there is a decreased surface for oxygen exchange and the potential for excessively increased pulmonary vascular resistance resulting in the persistent fetal circulation syndrome. These changes in the pulmonary vascular bed mimic those described by Meyrick and Reid (27) in continued hypoxia induced by exposure to low barometric pressure. This suggests that hypoxia may be a component of PFC inducing the pulmonary vascular changes.

The results from our work and others as noted above puts the use of indomethacin in pregnant women under severe question. Work in animals has shown that doses ranging from 2.5 to 5.0 $\mathrm{mg} / \mathrm{kg} /$ day cause significant ductal constriction $(36,42)$ and with a dose as low as $3.2 \mathrm{mg} / \mathrm{kg} /$ day for 4.5 to 5.0 days complete premature closure in 1 to $3 \%(36)$. Cardiopulmonary distress in infants of mothers receiving indomethacin (in doses of 100 to 200 $\mathrm{mg} /$ day) has been reported by several groups $(6,26,40)$. In one such group, PFC developed in $17 \%$ of the newborns (40), and in another group, PFC occurred in $50 \%$ with a $40 \%$ mortality among the infants with PFC (6).

Equally alarming is the possible causative role of PFC by salicylates. Significant ductal constriction by sodium salicylate was first reported in 1975 by Sharpe, with doses of 50 to $100 \mathrm{mg} /$ $\mathrm{kg}$ (42). Acetylsalicylic acid (ASA) was given to fetal lambs in a study by Heymann and Rudolph (17). They showed ductal constriction and changes in the combined ventricular output with an increase to the lungs, adrenals, and heart and a decrease to the brain, extremities, and remaining viscera (17). Apparently, this line of inquiry has not been pursued, and of particular concern 
are the reports that ASA and other salicylate containing analgesics are the most frequently consumed drugs during pregnancy $(5,8)$. Salicylates readily cross to the fetus via the placenta, resulting in tissue levels (excepting the brain) that are equal to the maternal blood level $(5,8)$. Inasmuch as the fetal renal excretion is less rapid, increased tissue level can occur (5). ASA used late in pregnancy has been shown to cause decreased birthweights, an increased number of stillbirths and an overall increase in neonatal deaths (5). The research work that has been done indicates that salicylates may be causative agents of PFC and the use of salicylates by pregnant women must be carefully examined. Further work must be done to determine the risks, particularly in the last trimester.

\section{REFERENCES AND NOTES}

1. Arcilla, R. A., Thilenius, D. G., and Ranniger, K.: Congestive heart failure from suspected ductal closure in utero. J. Pediatr., 75: 74 (1969).

2. Bucciarelli, R. L., Egan, E. A., Gessner, I. H., and Eitzman, D. V.: Persistence of fetal cardiopulmonary circulation: one manifestation of transient tachypnea of the newborn. Pediatrics, 58: 192 (1976).

3. Bucciarelli, R. L., Nelson, R. M., Egan, E. A., Eitzman, D. V., and Gessner, I H.: Transient tricuspid insufficiency of the newborn: a form of myocardia dysfunction in stressed newborns. Pediatrics, 59: 330 (1977).

4. Burri, P. H.: The postnatal growth of the rat lung. Anat. Rec., 180: 77 (1974).

5. Corby, D. G.: Aspirin in pregnancy: maternal and fetal effects. Pediatrics, 62: 930 (1978)

6. Csaba, I. P., Sulyok, E., and Ertle, T.: Relationship of maternal treatment with indomethacin to persistent fetal circulation syndrome. J. Pediatr., 92: 484 (1978).

7. Elias, H., Hennig, A., and Schwartz, D. E.: Sterology: applications to biomedical research. Physiol. Rev., 51: 158 (1971).

8. Elis, J., Sechserova, M., Stribny, J., and Drabkova, J.: The distribution of sodium salicylate in the human fetus. Int. J. Clin. Pharmacol., 16: 365 (1978)

9. Friedberg, D. Z., and Dechler, H. W.: Circulatory physiology in isolated pulmonary hypoplasia: persistent fetal circulation. Cardiology, 59: 154 (1974).

10. Friedman, W. F., Fitzpatrick, K. M., Merritt. T. A., and Feldman, B. H.: The patent ductus arteriosus. In: Clinics in Perinatology. Vol. 5, p. $411-436$ (W. B Saunders \& Co., St. Louis, 1978).

11. Friedman, W. F., Molony, D. A., and Kirkpatrick, S. E.: Prostaglandins: physiological and clinical correlations. In: Advances in Pediatrics, p. 151 (Yearbook Medical Publications, Inc., Chicago, 1978).

12. Friedman, W. F., Printz, M. P., and Kirkpatrick, S. E.: Blockers of prostaglandin synthesis: a novel therapy in the management of the premature human infan with patent ductus arteriosus. In: F. Coceani, P. M. Olley: Advances in Prostaglandins and Thromboxanes. Vol. 4, Chap. 33, p. 373-382 (Raven Press, New York, 1978)

13. Gersony, W. M.: Persistent fetal circulation: a commentary. J. Pediatr., 82: 1103 (1973)

14. Harker, L. C., Kirkpatrick, S. E., Friedman, W. F., and Bloor, C. M.: Persisten fetal circulation after indomethacin administration. Clin. Res., 28: 89A (1980).

15. Harker, L. C., Kirkpatrick, S. E., Friedman, W. F., and Bloor, C. M.: Effects of indomethacin on fetal pulmonary circulation. Lab. Invest., 42: 25 (1980).

16. Haworth, S. G., and Reid, L.: Persistent fetal circulation: newly recognized structural features. J. Pediatr., 88: 614 (1976).

17. Heymann, M. A., and Rudolph, A. M.: Efrects of acetylsalicylic acid on the ductus arteriosus and circulation in fetal lambs in utero. Circ. Res., 38: 418 (1976).

18. Hoskins, E. J., Kirkpatrick, S. E., and Friedman, W. F.: Pulmonary-aortic pressure gradients as an index of the caliber of the fetal ductus arteriosus. Am J. Obstet. Gynecol., 135: 543 (1979).

19. Kohler, H. G.: Premature closure of the ductus arteriosus: a possible cause of intrauterine circulatory failure. Early Hum. Dev., 2: 15 (1978).

20. Levin, D. L.: Morphologic analysis of the pulmonary vascular bed in congenital left-sided diaphragmatic hernia. J. Pediatr., 92: 805 (1978).

21. Levin, D. L., Heymann, M. A., Kitterman, J. A., Gregory, G. A., Phibbs, R. H., and Rudolph, A. M.: Persistent pulmonary hypertension of the newborn. J Pediatr., 89: 626 (1976).

22. Levin, D. L., Hyman, A. I., Heymann, M. A., and Rudolph, A. M.: Fetal hypertension and the development of increased pulmonary vascular smooth muscle: a possible mechanism for persistent pulmonary hypertension of the newborn infant. J. Pediatr., 92: 265 (1978).
23. Levin, D. L., Mills, L. J., and Parkey, M.: Morphologic development of the pulmonary vascular bed in experimental coarctation of the aorta. Circulation, 160: 349 (1979)

24. Levin, D. L., Mills, L. J., Parkey, M., Garriott, J., and Campbell, W.: Constriction of the fetal ductus arteriosus after administration of indomethacin to the pregnant ewe. J. Pediatr., 94: 647 (1979)

25. Levin, D. L., Mills, L. J., and Weinberg. A. G.: Hemodynamic, pulmonary, vascular and myocardial abnormalities secondary to pharmacologic constriction of the fetal ductus arteriosus. Circulation, 60: 360 (1979).

26. Manchester, D., Margolis, H. S., and Sheldon, R. E.: Possible association between maternal indomethacin and primary pulmonary hypertension of the newborn. Am. J. Obstet. Gynecol., 126: 467 (1976).

27. Meyrick, B., and Reid, L.: The effect of continued hypoxia on rat pulmonary artery circulation - an ultrastructural study. Lab Invest., 38 : 188 (1978).

28. Mobley, A., and Page, E.: The surface area of sheep cardic Purkinje fibers. J. Physiol. (Lond.), 220: 547 (1972).

29. Naeye, R. L.: Arteriolar abnormalities with chronic systemic hypertension. Circulation, 35: 662 (1967).

30. Nacye, R. L.: Pulmonary vascular changes with chronic unilateral pulmonary hypoxia. Circ. Res., 17: 160 (1965).

31. Naeye, R. L., and Liedtke, A. J.: Consequences of intramyocardial arterial lesions in aortic valvular stenosis. Am. J. Pathol., 85: 569 (1976).

32. Nacye, R. L., Shochat, S. J., Whitman, V., and Maisels, M. J.: Unsuspected pulmonary vascular abnormalities associated with diaphragmatic hernia. Pediatrics, 58: 902 (1976).

33. Nielson, H. C., Riemenschneider, T. A., and Jaffe, R. B.: Persistent transitional circulation. Radiology, 120: 649 (1976).

34. Page, E., and McCallister, L. P.: Quantitative electron microscopic description of heart muscle cells: application to normal, hypertrophied, and thyroxin-stimulated hearts. Am. J. Cardiol., 31: 172 (1973).

35. Page, E., McCallister, L. P., and Power, B.: Stereological measurements of cardiac ultrastructures implicated in excitation-contraction coupling. Proc. Natl. Acad. Sci. U. S. A., 68: 1465 (1971)

36. Powell, J. G and Cochrane, R. L. The effects of the administration of fenoprofen or indomethacin to rat dams during late pregnancy, with special reference to the ductus arteriosus of the fetuses and neonates. Toxicol. Appl. Pharmacol., 45: 783 (1978).

37. Radford, D. J.: Persistent fetal circulation: two cases with myocardial dysfunction and severe acidosis. Med. J. Aust., I: 27 (1979).

38. Riggs, T., Hirschfield, S., Fanaroff, A., Liebman, J., Fletcher, B., and Meyer, R.: Persistence of fetal circulation syndrome: an echocardiographic study. J. Pediatr., 91 : 626 (1977)

39. Rowe, R. D.: Abnormal pulmonary vasoconstriction in the newborn. Pediatrics, 59: 318 (1977).

40. Rubatelli, F. F., Chiazza, M. L., Zanardon, V., and Cantarutti, F.: Effect on neonate of maternal treatment with indomethacin. J. Pediatr., 4: 161 (1979).

41. Sharpe, G. L., Thalme, B., and Larsson, K. S.: Studies on closure of the ductus arteriosus. XI. Ductal closure in utero by a prostaglandin synthestase inhibitor. Prostaglandins, 8: 363 (1974).

42. Sharpe, G. L., Larsson, S. L and Thalme, B.: Studies on closure of the ductus arteriosus. XIII. In utero effect of indomethacin and sodium salicylate in rats and rabbits. Prostaglandins, 19: 585 (1975).

43. Silverstein, F. E., Ellis, K., and Casarella, W. J.: Persistence of the fetal circulation: radiologic considerations. Am. J. Roentgenol., 128: 781 (1977).

44. Snedecor, G. W., and Cochran. W. G.: Statistical Methods. Ed. 6 (lowa State University Press, Ames, IA, 1973).

45. Tudehope. D. I.: Persistent pulmonary hypertension of the newborn. Med. J. Aust., I: 13 (1979)

46. Wohl, M. E. B., Griscom, N. T., Strieder, D. J., Schuster, S. R., Treves, S., and Zwerdling, R. G.: The lung following repair of congenital diaphragmatic hernia. J. Pediatr., 90: 405 (1977)

47. Presented in preliminary form at the Annual Meeting of the Western Section of the American Federation for Clinical Research, Carmel, CA. February 6-8, 1980 (14), and at the Sixty-Ninth Annual Meeting of the International Academy of Pathology, New Orleans, Louisiana, February 25-29, 1980 (15).

48. The present address of Dr. S. E. Kirkpatrick is: 7920 Frost Street, Suite 304, San Diego, CA 92123.

49. The present address of Dr. W. F. Friedman is: Chairman, Department of Pediatrics, UCLA Hospital and Clinics, Los Angeles, CA 90024.

50. Requests for reprints should be addressed to: Dr. Colin M. Bloor, Department of Pathology M-012. UCSD School of Medicine, La Jolla, CA 92093 (USA)

51. This research was supported by Grant HL-07104 from the National Heart, Lung. and Blood Institute.

52. Received for publication April 14, 1980.

53. Accepted for publication July $22,1980$. 